\title{
ESTRESSE NO TRABALHO: ESTUDO DE CASO COM GERENTES QUE ATUAM EM UMA INSTITUIÇÃO FINANCEIRA NACIONAL DE GRANDE PORTE
}

\author{
Luciano Zille Pereira' \\ Clarissa Daguer Braga² \\ Antônio Luiz Marques ${ }^{3}$
}

\section{Resumo}

Com o objetivo de identificar os principais fatores causadores e diagnosticar o nível de estresse ocupacional na função gerencial em uma instituição financeira privada de âmbito nacional, com atuação na cidade de Belo Horizonte/MG, esta pesquisa, de natureza descritiva e explicativa, utilizando o MTEG (ZILLE, 2005), apontou a insegurança nas relações de trabalho, as metas super dimensionadas, o nível de cobrança excessiva, o quadro de funcionários aquém das necessidades da instituição e dificuldades nas relações pessoais, bem como algumas das principais causas de tensão excessiva no ambiente de trabalho, capazes de explicar níveis importantes de estresse para esta categoria funcional. Os resultados revelaram que cerca de 150 dos 168 gerentes pesquisados, ou seja, $89,10 \%$ foram diagnosticados com um quadro de estresse. Dentro desse diagnóstico, 59 gerentes $(35,21 \%)$ apresentaram estresse de leve a moderado; 69 (40,97\%) estresse intenso; e 22 (12,92\%) estresse muito intenso.

Palavras-chave: Estresse ocupacional. Fontes de tensão. Função gerencial. Instituições financeiras.

\section{INTRODUÇÃO}

As novas formas de organização do trabalho enfatizam o desenvolvimento de múltiplas habilidades por parte do trabalhador, que deve ser capaz não apenas de

' Doutor em Administração Universidade Federal de Minas Gerais, UFMG. Professor do Departamento de Ciências Administrativas da Universidade Federal de Minas Gerais - UFMG. Endereço: Rua Camapuã 700 Apto. 602, Belo Horizonte, MG, CEP 30430-450. E-mail: Izille@face.ufmg.br.

2 Mestranda em Administração do Centro de Pós-graduação e Pesquisa em Administração da Universidade Federal de Minas Gerais - CEPEAD/UFMG. Endereço: Rua Curitiba, 832 - $11^{\circ}$ andar, Bairro Centro, Belo Horizonte, MG, CEP 30 I70- I20. E-mail: cdb@ cepead.face.ufmg.br.

3 Doutor em Administração pela Aston Business School. Professor Associado do Departamento de Ciências Administrativas da Universidade Federal de Minas Gerais - UFMG. Endereço: Av. Antônio Carlos, 6627, $4^{\circ}$ andar, sala 4054, Campus Universitário, Belo Horizonte, MG, CEP 3 1270-90 I. E-mail: marques@face.ufmg.br. Artigo recebido em: 05/I I/2007. Aceito em: 15/05/2008. Membro do Corpo Editorial Científico responsável pelo processo editorial: Prof. João Nilo Linhares. 
prever problemas e desenvolver soluções alternativas, mas também de sugerir novas linhas de ação. Para os trabalhadores que continuam em seus postos, as inovações exigem maior qualificação, viabilizando ao máximo o aproveitamento da tecnologia. Além disso, de acordo com Goldberg (1986), nos últimos anos, a aceleração das mudanças vem contribuindo para provocar nos gerentes uma degradação da saúde mental, levando-os a importantes quadros de estresse. Em decorrência disso, tornam-se vulneráveis a diversos tipos de doenças, como as cardíacas, os distúrbios do sistema imunológico, as manifestações psicológicas diversas, entre outras.

O profissional de nível gerencial que se insere nessa nova realidade pertence a uma cultura empresarial em que, segundo Cooper (2005), as pessoas trabalham mais horas e mais arduamente, a fim de atingir o sucesso pessoal e as recompensas materiais. Neste momento o tema "Estresse Ocupacional" ganha importância e proporções ainda maiores do que em décadas anteriores. A partir da década de 1990, com a aceleração das mudanças organizacionais nas empresas brasileiras, e com a implementação de novos modelos de gestão, o gerente se vê com uma rotina diária cada vez mais desgastante e dá cada vez mais atenção às tensões decorrentes do ambiente de trabalho e ao estresse ocupacional (ROSSI, 2005; CHANLAT, 2005; PERREWÉ, 2005; SAUTER; MURPHY, 2005).

Assim, o estresse ocupacional, entendido como o estresse relacionado ao trabalho, tornou-se uma fonte de preocupação, uma vez que é reconhecido como um dos principais riscos ao bem-estar psicossocial do indivíduo (BATEMAN; STRASSER, 1983).

Nesse sentido, o presente trabalho tem como objetivo central identificar os principais fatores causadores de estresse, bem como diagnosticar o nível de estresse ocupacional na função gerencial, nos níveis de gerência de agência, de contas e operacional, em uma instituição financeira privada de âmbito nacional, com atuação na cidade de Belo Horizonte/MG. Para tanto, de acordo com a classificação de Vergara (2006), Meirelles e Gonçalves (2004), quanto aos fins, caracteriza-se pelo seu caráter descritivo e explicativo e quanto aos meios como estudo de campo, através de estudo de caso. A coleta de dados foi realizada através do questionário aderente ao Modelo Teórico de Explicação do Estresse Ocupacional em Gerentes - MTEG, desenvolvido por Zille (2005, p. 299), validado por meio de equações estruturais e suportado com base nas teorias sobre estresse ocupacional, tendo como referência os estudos de Cooper et al. (1998) Cooper (2002), Karasek e Torres (1996), Karasek (1998) Karasek et al. (2000), Moraes et al. (1990, 1992, 1995), Moraes, Marques e Zille (1998, 2000, 2002, 2003) e Couto (1987). As contribuições de Selye (1936, 1956, 1974), Friedman \& Rosenman (1974), French (1983), Goldberg (1986), Albrecht (1990), Levi (2003, 2005) e Sauter e Murphy (2005) também foram de grande importância para o presente estudo. 
Para contextualizar as transformações que vêm ocorrendo no ambiente organizacional é importante compreender as mudanças tecnológicas e seus impactos sobre a função gerencial, apresentados neste trabalho. O estresse ocupacional, suas abordagens conceituais, causas e sintomas também são discutidos para que se possa compreender e identificar as principais fontes de tensão, que podem ter como conseqüência o estresse associado ao trabalho do gerente. Na seqüência serão apresentados os procedimentos de investigação, a descrição da população pesquisada, os resultados e, à guisa de conclusões, apresenta-se considerações que puderam ser inferidas da pesquisa.

\section{AS MUDANÇAS TECNOLÓGICAS NO CONTEXTO ORGANIZACIONAL}

No decorrer da última década, e de forma intensa nos dias atuais, a introdução de novas tecnologias nas organizações impulsionou um amplo redesenho nas estruturas, nos processos e nos modelos de gestão de pessoas.

As novas tecnologias têm se tornado cada vez mais presentes na realidade administrativa, impulsionando os processos de mudança organizacional, uma vez que envolvem não apenas a necessidade de alterar políticas, procedimentos e estruturas, mas também introduzem novas formas de comportamento dos indivíduos e equipes e transformam, em maior ou menor escala, a cultura da organização. De acordo com Lemos (2000), o contexto atual se caracteriza por mudanças aceleradas nos mercados, nas tecnologias e nas formas organizacionais, e a capacidade de gerar e absorver inovações vem sendo considerada, mais do que nunca, crucial para que um agente econômico se torne competitivo. Nesse sentido, as organizações precisam, cada vez mais, desenvolver a arte de gerenciar a mudança para se manterem no mercado cada vez mais competitivo e globalizado.

Na visão de Nadler et al. (1989), o gerenciamento da mudança é bem sucedido quando a organização consegue se transpor do estado em que se encontra para o estado pretendido e o seu funcionamento futuro passa a atender às expectativas, isto é, funciona como planejado. Na visão do autor, outro aspecto importante é a adequação dos custos em relação ao processo de mudança, que é um estado ideal buscado pelas organizações. Além disso, para que um processo de mudança promovido pela inserção de novas tecnologias seja bem sucedido é preciso que ele seja visto, antes de tudo, como um processo de construção coletiva de novos significados acerca da realidade e do desenvolvimento de uma nova cultura organizacional.

De acordo com Weick e Quinn (1999), a nova tecnologia não é necessariamente a que se baseia em computadores, nem é aquela completamente inédita, mas sempre é a tecnologia nova para a empresa em questão, mesmo que ela não seja nova para o mercado. 
Neste contexto, a introdução de tecnologias nas organizações possibilita mudanças que não são apenas mudanças tecnológicas, mas também mudanças de crenças e valores organizacionais que refletem, em grande parte, no desempenho do trabalho de profissionais que se ocupam de funções gerenciais.

\subsection{As mudanças tecnológicas e suas implicações no trabalho dos gerentes}

As mudanças tecnológicas refletem em mudanças nos diversos níveis da organização, em especial, nos níveis gerenciais. Entendendo a reestruturação da empresa como o conjunto de mudanças significativas que visam à transformação das estruturas corporativas e organizacionais, provocam mudanças múltiplas, cujos riscos para a gerência podem assumir diferentes formas (ROULEAU, 2005).

Tendo em vista o contexto em transformação, a mudança tecnológica nas organizações pode ser considerada, enquanto aspecto inerente ao cotidiano organizacional e necessário para a sobrevivência da empresa no mercado global, competitiva e mutante; "afinal de contas tudo muda - os ambientes desestabilizam-se, os nichos desaparecem, as oportunidades banalizam-se" (MINTEZBERG; LAMPEL; AHLSTRAND, 2000, p. 106). Além disso, Weick e Quinn (1999, p. 381) salientam que "a mudança nunca começa porque ela nunca para", portanto, é um processo constante, e o ideal seria denominá-lo de mudando ao invés de mudança, para dar a idéia de processo contínuo.

No contexto da mundialização e face ao estabelecimento de novas regras de funcionamento e da introdução de novas tecnologias organizacionais, os gerentes passam a ter que assumir novas responsabilidades e enfrentar desafios diversos, bem como reformular toda uma lógica estabelecida e, assim, reconstruir um novo modo de pensar relativo aos problemas e aos princípios, às hipóteses, aos arcabouços teóricos e tecnológicos disponibilizados. O grupo gerencial constitui, assim, de acordo com Melo e Sperling (2002), peça fundamental nos processos de reestruturação e modernização organizacional, ao mesmo tempo em que sofre os impactos múltiplos de tais processos.

Para compreender os verdadeiros impactos que as transformações tecnológicas têm refletido na função gerencial é essencial que se entenda o gerente e a função gerencial, não só na perspectiva das novas formas de gestão, que são as que se apresentam no cenário atual estabelecido pelo mercado globalizado, mas também é importante que se conheça a perspectiva clássica da função gerencial, fazendo um percurso histórico até os dias atuais.

\subsection{O gerente e a função gerencial: da perspectiva clássica às novas formas de gestão}

Estudos que buscam entender as funções, os papéis e as habilidades dos gerentes não são recentes. $\mathrm{O}$ gerente aparece em meio a diversidades de abordagens 
e enfoques que constituem a administração, dotado de várias significações que vão desde o supervisor do processo de trabalho, intermediando o controle e o comando da organização, até as implicações que associam a esse profissional o sentido de líder.

Fayol (1949) enfatizava que o administrador de pessoas é aquele que tem por função planejar, organizar, coordenar, comandar e controlar o trabalho de uma unidade de comando. Outras representações sobre o que é o gerente são apontadas por outros autores, como Sloan (1963) que diz que o gerente é alguém que infunde seus valores pessoais e profissionais em toda a organização; Schumpeter (1938) retrata este profissional como um empreendedor e promotor de inovações; Simon (1947) o define como um tomador de decisões não-programadas, em um ambiente complexo e incerto e Katz e Kahn (1976) referem-se ao gerente como um líder eficaz, detentor de certos traços de personalidade específicos. Mas são Mintzberg (1973) e Stewart (1967) os precursores de uma série de observações mais aprofundadas sobre as atividades diárias dos gerentes.

Mintzberg (1973), com suas pesquisas, deixa, dentre várias, a contribuição de que o trabalho dos gerentes é caracterizado pela fragmentação das atividades, pelo ritmo de trabalho e pela preferência por contatos verbais. A partir dos registros de suas observações de campo, o autor formulou um conjunto dos principais papéis gerenciais (interpessoais, informacionais e decisórios), subdivididos em dez papéis secundários referentes ao tempo gasto do gerente no seu dia-a-dia. A síntese desses papéis nega que o trabalho do gerente, no contexto da crise, seja ordenado, contínuo, seqüencial, homogêneo, além de não ser derivado de suas próprias iniciativas nem de sua vontade transformada em decisões.

Stewart (1967) deixa como uma de suas importantes contribuições a constatação de que existem variações no trabalho dos gerentes em função de relações interpessoais. As pesquisas pioneiras sobre as atividades dos gerentes incluem também os trabalhos de Carlson (1951), que, com suas pesquisas, deixou a contribuição de que os gerentes têm jornadas fragmentadas, essencialmente em comunicações verbais; Sayles (1964), que com suas observações pode concluir que os gerentes são vistos como líderes, monitores e participantes no processo de trabalho e Kotter (1982) enfatiza a rede interpessoal de relacionamentos dos gerentes.

Mais recentemente, pesquisas como as de Motta (1991), Davel e Melo (2005), Aktouf(2005), Zille (2005), Marques, Morais e Portes (2003), Melo e Sperling (2002) e Kliksberg (1993) buscam retratar a função gerencial do ponto de vista da realidade atual das empresas, que se inserem em um contexto diferente dos das décadas anteriores e no qual predominam e predominarão, cada vez mais, a complexidade, a instabilidade e a incerteza, dando lugar a uma gerência que age em grande parte em meio à turbulência, em contraponto aos ambientes controlados e marcados pela maior racionalidade das décadas anteriores. 
Nesse sentido, o profissional de nível gerencial que se insere nessa nova realidade pertence a uma cultura empresarial em que, segundo Cooper (2005), as pessoas trabalham mais horas e mais arduamente, a fim de atingir o sucesso pessoal e as recompensas materiais. Neste momento o tema do Estresse Ocupacional ganha importância e proporções ainda maiores do que em décadas anteriores. É a partir da década de 1990, principalmente em relação à realidade brasileira, com as mudanças organizacionais mais evidentes e com os novos modelos de gestão que começa a se estabelecer, que o gerente se vê em uma rotina diária cada vez mais desgastante e dá cada vez mais atenção às tensões decorrentes das pressões excessivas vivenciadas no ambiente de trabalho, e como conseqüência disso, surge o estresse ocupacional (ROSSI, 2005; CHANLAT, 2005; PERREWÉ, 2005; SAUTER; MURPHY, 2005).

Assim, o estresse ocupacional, entendido aqui como o estresse relacionado ao trabalho, tornou-se uma fonte importante de preocupação, uma vez que é reconhecido como um dos riscos sérios ao bem-estar psicossocial do indivíduo (BATEMAN; STRASSER, 1983).

O estresse ocupacional aparece, então, como tema de preocupação crescente tanto no meio organizacional quanto no meio acadêmico quando o assunto em questão é o trabalho do profissional que ocupa função gerencial (ZILLE, 2005; ROSSI et al., 2005).

\section{ENTENDENDO O ESTRESSE OCUPACIONAL}

Stress é uma palavra derivada do latim. Durante o Século XVII ganhou conotação de adversidade ou aflição. No final do século seguinte, seu uso evoluiu para expressar força, pressão ou esforço. O conceito de stress não é novo, mas foi apenas no início do Século XX que estudiosos das ciências biológicas e sociais iniciaram a investigação de seus efeitos na saúde física e mental das pessoas, como sendo um estado do organismo após o esforço de adaptação que pode produzir deformação na capacidade de resposta do comportamento mental e afetivo, do estado físico e do relacionamento com as pessoas. Para fins deste trabalho o termo stress, em inglês, será grafado em português, estresse (NASCIMENTO et al., 1998).

As tendências recentes de reestruturação do trabalho e do emprego têm causado preocupações em muitos pesquisadores, como Cahill e Schnall (1999) e Quinlan, Mayhew e Bohle (2001), de que estes eventos tragam risco de estresse e como conseqüência doenças físicas e psicossomáticas ao indivíduo. Por exemplo, o aumento da jornada de trabalho, que é um fator comum na função gerencial, pode gerar preocupações de intensificação e sobrecarga de trabalho. $\mathrm{O}$ enxugamento e as práticas de emprego temporário podem prejudicar a capacidade dos trabalhadores e das organizações de acumular e reter o conhecimento sobre segurança, desencorajar o relato de riscos e acidentes ou a utilização dos serviços de saúde devido ao medo de perder do emprego.

De acordo com Zille (2005, p. 61), 
[...] as sociedades estão passando por um processo de intensificação do ritmo em que as mudanças acontecem. Aliado a essa conjuntura verificase uma deterioração da qualidade de vida dos indivíduos. Dessa forma, o estresse apresenta-se como uma variável importante, que vem atingindo os indivíduos de forma geral. Cada período da história contribui de maneira positiva para o desenvolvimento global, mas cobra um preço por esse benefício, sendo o estresse um dos preços mais habituais da atual época de turbulência sócio-cultural por que passa a humanidade.

Rifkin (1995) destaca que a situação do emprego está se modificando e milhares de trabalhadores estão perdendo seus postos de trabalho, uma vez que estão sendo substituídos, com maior intensidade, pelas chamadas tecnologias inteligentes, que vêem sendo desenvolvidas em larga escala em todo o planeta. Para o autor, esse novo mundo do trabalho está deixando os indivíduos alienados, vítimas de um acentuado estresse proveniente de pressões decorrentes de um ambiente de alta tecnologia e crescente insegurança.

Nesse sentido, para entender de forma mais consistente o estresse ocupacional, torna-se importante entender as abordagens conceituais que permitem uma visão global de manifestações desta natureza, que provocam como decorrência tensões nos indivíduos e em muitos casos, quadros de estresse.

\subsection{As abordagens conceituais do estresse ocupacional}

As abordagens bioquímica, psicológica e sociológica, que podem ser consideradas complementares e interligadas, são entendidas como as três principais abordagens conceituais referentes ao estresse ocupacional.

A abordagem bioquímica, ou seja, a fisiologia do estresse surgiu nas décadas de 1930 a 1950, influenciada pelos estudos de Selye (1936), primeiro pesquisador a estudar o estresse do ponto de vista bioquímico. O trabalho de Selye foi influenciado por pesquisadores que não estudaram diretamente o estresse, mas que proporcionaram importantes subsídios para a sua compreensão, como foi o caso do fisiologista francês Bernard, ao apontar a capacidade de manter a constância do equilíbrio interno como um dos traços mais característicos de todos os seres vivos e do fisiologista Cannon, que retomou o conceito de Bernard sobre a constância do equilíbrio interno, desenvolvendo-o e denominando-o de homeostase. Avançando em relação às constatações desses dois fisiologistas, Selye (1936), além da reação de alarme, descreveu outras duas fases, resistência e exaustão, relacionadas ao estresse. Para este autor, decorrentes do estado de tensão, diversas reações fisiológicas ocorrem no organismo com o objetivo de prepará-lo para enfrentar ou adaptar-se às fontes de pressão às quais o organismo está sendo submetido. 
A abordagem psicológica, que apresenta sua ênfase principal na compreensão da influência que a percepção e o comportamento do indivíduo são manifestados no processo de estresse, apresenta as seguintes vertentes: psicossomática; interacionista; behaviorista; psicopatologia do trabalho e a da psicologia social. Essas vertentes mostram que a abordagem psicológica, em relação aos estudos sobre estresse, não apresenta uma direção única, embora nas suas diversas vertentes apresente coerência em relação a determinados pressupostos. Importantes contribuições nessa abordagem foram atribuídas às pesquisas de Cooper, Cooper e Eaker (1988), uma vez que estes estudos ampliaram o entendimento sobre o complexo processo que envolve os seres humanos. No entanto, na visão de Cooper, Cooper e Eaker (1988), Lhuilhier, Mignèe e Raix (1990), Arnald, Robertson e Cooper (1991) e Morais, Marques e Zille (1998), o trabalho de Lazarus (1974) é considerado um marco importante para os estudos da abordagem psicológica, uma vez que o mecanismo psicológico é percebido como determinante no processo, associando-se ao desencadeamento de quadros de estresse.

Já a abordagem sociológica está relacionada à compreensão das diversas variáveis que se estabelecem no contexto da sociedade. Nesta abordagem, de acordo com Cassirer (1994), percebe-se uma dependência entre a visão de mundo do indivíduo e a sua realidade social. $\mathrm{O}$ indivíduo depende da estrutura social em que vive para estabelecer o seu universo simbólico, bem como para construir a sua cultura individual que servirá de base para interpretar os fatos ao seu redor, o que proporciona elementos para a sua identificação e diferenciação. De acordo com esta abordagem, conforme afirma Leontiev (1978), o desenvolvimento psíquico dos indivíduos está relacionado à estrutura cultural estabelecida e, nessa dimensão, as alterações culturais afetam diretamente os mecanismos psicológicos individuais. Nos dias atuais, a presença mais forte do estresse social revela uma alteração sociocultural que influencia o mecanismo psíquico e altera as condições ambientais nas quais o indivíduo está inserido, provocando influência no mecanismo biológico. Sendo assim, para a compreensão do estresse é de fundamental importância entender não só o indivíduo, no que se refere a seu mecanismo psicológico e o seu ambiente, como também os valores sociais e as suas transformações.

Essas abordagens permitem uma visão global das manifestações do estresses, sendo que a abordagem bioquímica permite uma observação principalmente no que se refere ao aspecto fisiológico e à abordagem psicológica, permitindo entender a importância dos mecanismos psicológicos no desencadeamento de quadros de estresse, além disso, a abordagem sociológica mostra a importância de se compreender as novas variáveis que se estabelecem dentro da sociedade para que se possa, então, interpretar as fontes de pressão à luz de cada nova realidade que se estabelece. Essas abordagens conceituais mostram sob diversas óticas como podem ser entendidas e estudadas as manifestações relacionadas ao estresse, constituindo-se em importante base teórica para realização de estudos nessa área, como é o caso do presente trabalho. 
A seguir será apresentado com base na Figura 1 o Modelo Teórico utilizado neste trabalho, para explicar o estresse ocupacional em gerentes (MTEG). Esse modelo foi desenvolvido por Zille (2005), validado por meio de equações estruturais e suportado com base nas teorias sobre estresse ocupacional, tendo como referência os estudos de Cooper et al. (1998), Cooper (2002), Karasek e Torres (1996), Karasek (1998), Karasek et al. (2000), Moraes et al. (1990, 1992, 1995), Moraes, Marques e Zille (1998, 2000, 2002, 2003) e Couto (1987). As contribuições de Selye (1936, 1956, 1974), Friedman \& Rosenman (1974), French (1983), Goldberg (1986), Albrecht (1990), Levi (2003, 2005), Sauter e Murphy (2005) também foram de grande importância para o presente estudo.

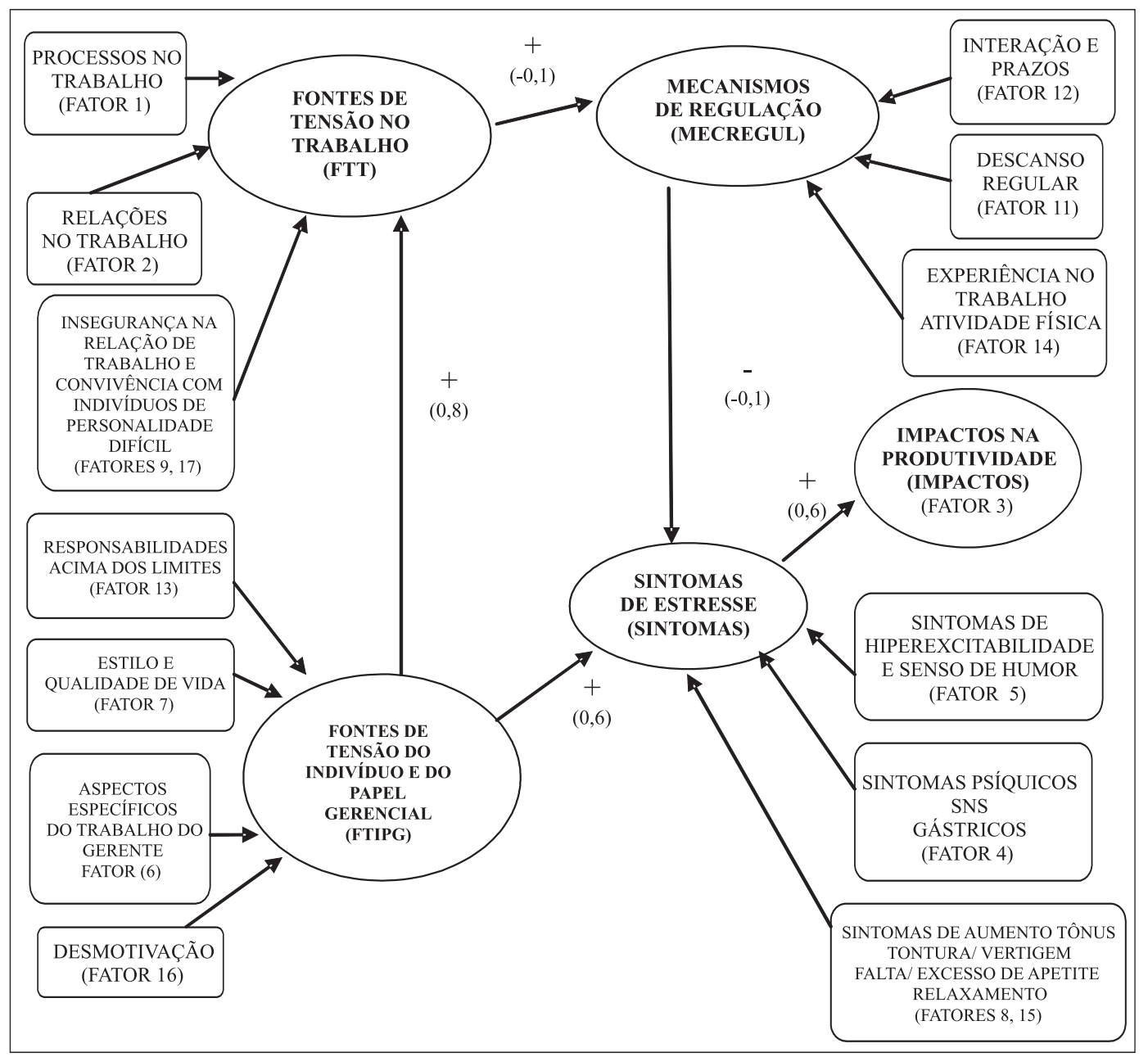

Figura 1 - Modelo teórico para explicar o estresse ocupacional em gerentes (MTEG)

Fonte: ZILLE (2005, p.191) 
Legenda: 1) As indicações dos valores entre parênteses no modelo teórico como $+(0,8) ;+(-0,1)$ .... referem-se aos coeficientes de caminho estimados pelo PLS - Partial Least Squares, como intervalos de confiança a 5\%, para explicação dos construtos do modelo teórico. 2) A numeração relativa aos fatores dos constructos de segunda ordem constantes do modelo teórico, referem-se aos indicadores dos respectivos fatores extraídos através da Matriz Rotacionada de Componentes Final (ZILLE, 2005 , p. 148-149 e 186).

O modelo em referência é composto por cinco construtos de primeira ordem (fontes de tensão no trabalho; fontes de tensão do indivíduo e do papel gerencial; mecanismos de regulação; sintomas de estresse; e impactos na produtividade). Cada construto de primeira ordem é explicado pelos respectivos construtos de segunda ordem, que por sua vez estão relacionados aos seus indicadores. Exceção se faz ao construto impactos na produtividade que é explicado de forma direta pelos indicadores relacionados. Aderente a este modelo tem-se o questionário MTEG que foi utilizado nesta pesquisa.

Aprofundando a análise do modelo teórico, como foi possível observar na Figura 1 , as fontes de tensão no trabalho são explicadas por três construtos de segunda ordem que são os processos de trabalho; as relações no trabalho; e a insegurança nas relações no trabalho e convivência com indivíduos de personalidade difícil. As fontes de tensão do individuo e do papel gerencial, por sua vez, são explicadas por responsabilidades acima dos limites; estilo e qualidade de vida; aspectos específicos do trabalho do gerente; e desmotivação. Já os mecanismos de regulação são explicados por interação e prazos; descanso regular; e experiência no trabalho e atividade física. Os sintomas de estresse são explicados pelos construtos de segunda ordem sintomas de hiperexitabilidade e senso de humor; sintomas psíquicos do sistema nervoso, simpático e gástricos; e sintomas de aumento do tônus, tontura ou vertigem, falta ou excesso de apetite e relaxamento. O construto impactos na produtividade é explicado de forma direta pelos seus respectivos indicadores, que são em número sete (ZILLE, 2005, p. 191).

\subsection{Tensão: conceitos, causas e sintomas}

A tensão está intimamente ligada às pressões decorrentes das atividades do executivo. De acordo com Couto (1987, p. 75), "tensão é um estado em que o organismo encontra-se preparado para agir, fisiológica e psicologicamente". O autor também destaca que a propensão ao estresse tem como causa primordial a dependência dos outros ao alcance de seus próprios resultados. Assim, o ponto fraco do gerente extremamente estressado é a tensão, uma vez que, nesse estado, alguns órgãos do corpo humano, tais como o coração, o pulmão, o fígado e os músculos têm o seu funcionamento alterado. Aqui é possível observar que a tensão, apesar de ser um estado em que o organismo encontra-se preparado para agir, torna-se nociva quando ocorre de forma excessiva. 
Quanto às causas das tensões, podendo ter como conseqüência o estresse ocupacional, o modelo teórico Tensões no Trabalho, desenvolvido por Karasek et al. (1998), enfatiza dois importantes estressores. Segundo o autor, os riscos à saúde física-mental do trabalhador pelo estresse, ocorrem quando as altas demandas psicológicas, ou pressões relacionadas às habilidades no trabalho, e a autoridade de tomada de decisões combinam com uma baixa abrangência de controle ou decisão ao deparar com essas demandas.

Os sintomas de tensão ou a propensão à tensão, segundo Couto (1987, 2007), variam de acordo com os traços de personalidade. É importante salientar que a tensão não é um traço inerente à personalidade do indivíduo, mas sim uma característica adquirida ao longo de sua vida. No caso dos gerentes, os fatores relacionados à sua profissão são determinantes para desencadear desde uma fleuma até altos níveis de tensão, podendo chegar à estafa, isto é, esgotamento físico-mental, em que "a capacidade laborativa e emocional do indivíduo vai à zero" (COUTO, 1987, p. 76).

Para Couto $(1987,2007)$, os fatores potencialmente desencadeadores de tensão próprios do trabalho daqueles que exercem função gerencial são principalmente o relacionamento constante com pessoas difíceis (personalidade difícil); mudança de cidade em função do trabalho; muitos prazos, e a maioria urgentes; excesso de viagens; tensão inerente a responsabilidades por decisões finais, incluindo decisões que podem afetar a vida de muitas pessoas; administrar fusões de setores, unidades ou empresas; reestruturar unidade com baixo desempenho; conviver com diretores ou acionistas hostis; falta de apoio da matriz; competitividade no mercado; ter de corrigir erros de antecessores. Segundo o autor, a função gerencial está relacionada à chamada atividade de alta desensidade, que se caracteriza pelo uso constante da memória imediata, micro decisões constantes e atividades que envolvem importante carga emocional (COUTO, 1996, p. 334).

Outra colaboração importante quanto aos indicadores que explicam os níveis de tensão excessiva nos processos de trabalho encontra-se nos estudos de Zille (2005). Para o autor são diversos os fatores que podem ser classificados como fontes importantes de tensão no trabalho. Merecem destaque: realização de várias atividades ao mesmo tempo com alto grau de cobrança; filosofia de trabalho pautada pela obsessão e compulsão por resultados; relacionar-se com indivíduos de personalidade difícil, muitas vezes com algum tipo de patologia comportamental; conviver com muitos prazos e cronogramas apertados; excesso de metas; sobrecarga em decorrência da tecnologia (e.mail's, softwares, sistemas integrados de gestão, entre outros) e trabalho complexo e desgastante.

A seguir, buscando ampliar o panorama conceitual sobre estresse ocupacional, apresentam-se os resultados da investigação que buscou identificar os principais fatores causadores de tensão excessiva no ambiente de trabalho, bem como diagnosticar o nível de estresse ocupacional na função gerencial de uma instituição do setor bancário de âmbito nacional com atuação na cidade de Belo Horizonte/MG. 


\section{O ESTRESSE OCUPACIONAL EM GERENTES DO SETOR BANCÁRIO: ASPECTOS METODOLÓGICOS E RESULTADOS}

De acordo com a taxionomia apresentada por Vergara (2006), Meirelles e Gonçalves (2004), sobre os tipos e métodos de pesquisa, o presente estudo caracteriza-se por ser uma pesquisa explicativa, cujo objetivo é esclarecer quais fatores contribuem, de alguma forma, para ocorrência de determinado fenômeno, no caso, o estresse; e descritiva, na medida em que apresenta as características de determinada população ou fenômeno ou mesmo estabelece relação entre as variáveis estudadas. Assim, o enfoque explicativo subsidiado pelo descritivo mostrou-se adequado mediante um estudo de caso que buscou analisar e explicar os impactos que uma determinada função ocupacional, no caso a de gerente, proporciona em uma classe específica de trabalhadores.

A população pesquisada constituiu-se pelos empregados que atuam em nível gerencial intermediário (gerentes de agências, de contas e operacionais) de uma instituição financeira privada de âmbito nacional, com atuação na cidade de Belo Horizonte - MG. A amostra foi de $100 \%$ da população em estudo, sendo composta por 56 gerentes de agências, 56 gerentes de contas e 56 gerentes operacionais em um total de 168 indivíduos

A estratégia de pesquisa adotada foi o survey, utilizando-se também observação para validar as inferências qualitativas. Utilizou-se do questionário aderente ao Modelo Teórico proposto para explicar o estresse ocupacional em gerentes (MTEG), desenvolvido por Zille (2005), e os dados quantitativos foram processados através do o software Excel.

\subsection{Apresentação dos Resultados}

Destaca-se que dos gerentes pesquisados, $55 \%$ são do sexo masculino e $45 \%$ são do sexo feminino. Em relação à faixa etária os dados mostram uma variação entre 27 e 55 anos, sendo que a moda, 133 gerentes, encontra-se na faixa de 31 a 45 anos.

Com relação à distribuição por estado civil, tempo na função e tempo que trabalha na instituição, verificam-se os seguintes dados: a maior parte dos gerentes (77\%) encontra-se casada, $86 \%$ exercem a função há no máximo dez anos e 44,5\% trabalham de dez a quinze anos na instituição pesquisada. Todos os gerentes são contratados para uma jornada de trabalho de 44 horas semanais, mas apenas 19\% alegaram cumprir essa jornada. A maioria (81\%) trabalha além desta carga de trabalho.

Quanto ao nível educacional, em termos globais, verifica-se que 97\% possuem graduação e 30\% possuem o nível de Pós-Graduação (Especialização Lato Sensu).

Em relação à atividade física, $29 \%$ dos gerentes praticam com regularidade, $88 \%$ não fumam e $62 \%$ fazem uso de bebida alcoólica, de forma social, semanalmente. 
Para análise do nível de intensidade de estresse ocupacional apontado pela pesquisa, tomou-se como referência a escala desenvolvida por Zille (2005, p. 222, 223): Ausência de Estresse $<1,75$; Estresse Leve a Moderado $\geq 1,75 \mathrm{a}<2,46$; Estresse Intenso $\geq 2,46 \mathrm{a}<3,16$; e Estresse Muito Intenso $\geq 3,16$

Os conceitos utilizados em relação à categorização do estresse foram os seguintes: Ausência de Estresse - significa um estado de bom equilíbrio entre as demandas psíquicas advindas do ambiente, tais como trabalho, família e social, entre outras, e a estrutura psíquica do indivíduo. Estresse Leve a Moderado - indica a ocorrência de manifestações de estresse, no entanto em grau compensado, podendo não gerar impactos importantes nos diversos ambientes de interação do indivíduo. Estresse Intenso - indica a ocorrência de manifestações de estresse num grau elevado, podendo gerar impactos importantes no indivíduo. As condições orgânicas e psíquicas já podem estar apresentando alterações e, em alguns casos, os indivíduos necessitam de tratamento e acompanhamento psicológico, podendo necessitar também de tratamento clínico. Estresse Muito Intenso - indica a ocorrência de manifestações de estresse num grau muito elevado, gerando impactos significativos nos diversos ambientes onde o indivíduo opera. As condições orgânicas e psíquicas apresentam alterações importantes e, os casos dessa intensidade necessitam de tratamento e acompanhamento clínico e psicológico (ZILLE, 2005, p. 223, 225, 226 e 288).

A Tabela 1 mostra os gerentes pesquisados por grupo funcional (gerentes de agências, de contas e operacionais) e a relação com o nível de estresse identificado.

Tabela 1: Nível de estresse ocupacional dos gerentes por categoria funcional

\begin{tabular}{l|c|c|c|c|c|c|c|c}
\hline \multirow{2}{*}{ Nível de estresse } & \multicolumn{5}{|c|}{ Nível hierárquico } & $\begin{array}{c}\text { Total por } \\
\text { nível de } \\
\text { estresse }\end{array}$ & $\%$ \\
\cline { 2 - 9 } & G.A & $\%$ & G.C. & $\%$ & G.O & $\%$ & 19 & $11,31 \%$ \\
\hline Ausência & 3 & $5,36 \%$ & 2 & $3,57 \%$ & 14 & $25,00 \%$ & 59 & $35,12 \%$ \\
\hline Leve a moderado & 21 & $37,50 \%$ & 23 & $41,07 \%$ & 15 & $26,7 \% 9$ & 59 \\
\hline Intenso & 28 & $50,00 \%$ & 20 & $35,71 \%$ & 20 & $35,71 \%$ & 68 & $40,48 \%$ \\
\hline Muito intenso & 4 & $7,14 \%$ & 11 & $12,50 \%$ & 7 & $12,50 \%$ & 22 & $13,09 \%$ \\
\hline TOTAL & 56 & $100 \%$ & 56 & $100 \%$ & 56 & $100 \%$ & 168 & $100 \%$ \\
\hline
\end{tabular}

Fonte: Dados da pesquisa

Legenda: GA - Gerente de Agências; GC - Gerentes de Contas; GO - Gerentes Operacionais

De acordo com a Tabela 1, 90 gerentes, ou 53,57\% da população pesquisada, encontram-se no nível de estresse intenso ou muito intenso. O resultado obtido demonstra certo grau de preocupação, uma vez que esse nível de estresse extrapola uma condição de normalidade e os indivíduos passam a apresentar sintomas tais como: 
nervosismo excessivo, ansiedade, dificuldade de concentração no trabalho, angústia, fadiga, irritabilidade sem causa aparente, depressão, entre outros, que afetam de forma significativa a condição de trabalho e conseqüentemente o desempenho na função.

Ao analisar os indivíduos por grupo funcional, verifica-se que os gerentes de agência são os que apresentam uma maior incidência de estresse, localizando-se nos níveis intenso e muito intenso $(57,14 \%)$. Os gerentes de contas e operacional apresentam também um estresse significativo, nos níveis intenso ou muito intenso, na ordem de $48,21 \%$.

A ausência de estresse é verificada em somente 19 gerentes, o que significa $11,31 \%$ da amostra pesquisada.

Em relação às Fontes de Tensão Excessiva no Trabalho, as identificadas como as mais importantes na geração dos quadros de estresse foram a insegurança na relação de trabalho; as metas excessivas e muitas vezes inatingíveis; o excesso de pressão e cobranças por resultados; o convívio com indivíduos de personalidade difícil; a dificuldade na administração do tempo; e trabalhar com um quadro de empregados aquém das necessidades da instituição, o que na maioria das vezes implica em acúmulo de atividades paralelas, como por exemplo, o atendimento telefônico concomitante com o atendimento pessoal de clientes nas agências. Observou-se que em decorrência dessas situações, comportamentos de mau humor e dificuldades nas relações humanas no trabalho foram observados como uma tônica no ambiente da organização.

Outros aspectos específicos relacionados ao trabalho dos gerentes também causadores de tensão excessiva foram identificados como: conhecer o que é qualidade de vida e sua importância e não ter tempo de praticar esses conceitos, devido à absorção pelo trabalho; ter dificuldade de compatibilizar os compromissos de trabalho com os compromissos de família e sociais, entre outros; vivenciar conflitos por ter que, ao mesmo tempo, ser inovador e dotado de autonomia e estar sujeito às normas da organização; vivenciar conflitos por perceber-se em sobrecarga e não ter como questionar, por exercer função de confiança (gerencial); ter de compatibilizar entre a necessidade de descentralização e a concentração de poder no topo da empresa; ter dificuldade de conciliar a necessidade de trabalhar em modelo participativo e a necessidade de isolamento, em função da competitividade; não poder agir de forma autoritária e ter que ser autoritário em determinadas ocasiões; conviver com situações de tensão excessiva inerentes às relações humanas do trabalho; e sentir que os resultados estão de bom tamanho, mas não poder manifestar essa percepção para a organização, tendo que solicitar à equipe resultados ainda mais desafiadores.

Dos aspectos citados foi possível observar que todos influenciam de alguma forma no nível de estresse dos gerentes, no entanto, o que aparece com maior intensidade no grupo de gerentes com estresse intenso ou muito intenso é conhecer o que é qualidade de vida e sua importância e não ter tempo de praticar esses conceitos, devido à absorção pelo trabalho. A incidência foi de $65,93 \%$ nesse grupo gerencial. 
Analisando os mecanismos de regulação foi possível observar que os gerentes de contas encontram-se mais vulneráveis. $22 \%$ consideram a periodicidade de cobrança inadequada; e $28 \%$ consideram nunca ser possível atrasar os cronogramas de trabalho. $12 \%$ têm a percepção de que nunca é possível ter um canal aberto na instituição para discutir situações difíceis e de tensão importante. Esta situação agrava-se pelo fato desses gerentes serem diretamente responsáveis pela produção, envolvendo o cumprimento das metas, enquanto os gerentes de agências focam mais no papel de coordenar e dirigir os trabalhos administrativos.

Em relação à experiência pessoal como subsídio para reduzir a tensão no ambiente de trabalho, todos consideram muito relevante, como também a cooperação entre os pares que, para a maioria dos gerentes pesquisados, muitas das vezes é possível. Observou-se que estes mecanismos de regulação são utilizados freqüentemente pelos gerentes.

Verificou-se também que em termos de tempo para relaxar e descansar, 100\% da amostra estudada realiza esta prática com certa regularidade, no entanto, não demonstrando suficiência para neutralizar as ocorrências de estresse. Por fim, identificou-se que $26 \%$ dos gerentes não têm o hábito de realizar exercícios físicos, ou seja, são sedentários.

\section{CONSIDERAÇÕES FINAIS}

Considerando o objetivo central deste trabalho, através da utilização do MTEG Modelo Teórico para Explicar o Estresse Ocupacional em Gerentes, desenvolvido por Zille (2005), foi possível diagnosticar o nível de estresse ocupacional numa amostra de 168 gerentes que atuam em 100\% das agências de uma instituição financeira privada de âmbito nacional, na cidade de Belo Horizonte/MG, referente aos três níveis gerenciais: gerentes de agências, de contas e operacionais.

Os resultados globais apontaram que cerca de 150 dos gerentes pesquisados, ou $89,10 \%$, foram diagnosticados com quadro de estresse, sendo: 59 , ou $35,21 \%$, com estresse leve a moderado; 69 , ou $40,97 \%$, com estresse intenso; e 22 , ou $12,92 \%$, com estresse muito intenso.

Outra constatação da pesquisa foi com relação ao gênero. Verificou-se que os gerentes de sexo feminino, comparado aos de sexo masculino apresentam um percentual de estresse ligeiramente superior, ou seja, $90,71 \%$, ou 64 , dos gerentes do sexo feminino apresentam quadro de estresse, sendo $43,55 \%$, ou 32 , na faixa de estresse intenso; enquanto que no sexo masculino, $87,88 \%$, ou 84 dos gerentes, também apresentam quadro de estresse, sendo $39,02 \%$, ou 37 , na faixa de estresse intenso.

Esses dados, se comparados com o trabalho de Zille (2005, p. 231), apresentam a mesma constatação, ou seja, o estresse ocorre com maior freqüência em gerentes 
do sexo feminino. "O teste de inferência estatística permite generalizar que a mulher na função gerencial tem mais estresse do que os homens $(\mathrm{p}<0,01)$ ”.

Outra constatação relevante é que o nível de estresse ocupacional dos gerentes está diretamente relacionado ao tempo de exercício na função. Verificou-se uma tendência de aumento no nível de estresse na medida em que os gerentes acumulam maior tempo de exercício na função gerencial.

Em termos gerais os dados desta pesquisa são coerentes com os dados da pesquisa realizada por Zille (2005) com gerentes de organizações brasileiras de setores diversos, incluindo o setor bancário. Com relação a esse setor em específico, a pesquisa do autor foi realizada em uma instituição que teve sua origem na década de 1940 e constitui-se, atualmente, uma das principais instituições financeiras privadas do país. A pesquisa verificou que $100 \%$ dos gerentes pesquisados apresentavam quadro de estresse, sendo que 38\% dos indivíduos encontravam-se em nível de estresse intenso ou muito intenso. Além disso, verificou-se que a gerência intermediária é a que sofre maior intensidade de pressão advinda do contexto de trabalho, o que, conseqüentemente, tende a apresentar maior incidência de estresse. Os principais problemas identificados na pesquisa estão relacionados ao estabelecimento de metas sem a participação dos envolvidos, muitas vezes com objetivos definidos muito além da capacidade de realização, associado ao excesso e ao rigor nas cobranças, o que vai ao encontro dos resultados da pesquisa apresentada no presente estudo.

A análise da essência do trabalho bancário e as transformações ocorridas no setor, concatenadas aos resultados da pesquisa, apontam para questões importantes como a atuação de alguns gerentes fora dos padrões éticos, impulsionados principalmente pela competição acirrada; a fixação de metas intangíveis e consecutivas sem a participação dos envolvidos; e os avanços tecnológicos que reduzem a necessidade dos recursos humanos, mas que aumentam as responsabilidades e os trabalhos a serem executados por aqueles que permanecem na instituição.

Considera-se que a pesquisa sobre estresse no setor bancário está em constante construção, precisando ser realizada e refeita o quanto possível para que se possa, cada vez mais, conhecer em profundidade esse setor, visando alternativas para diminuir os níveis de estresse e melhorar as condições de trabalho desses trabalhadores.

\title{
STRESS AT WORK: A CASE STUDY INVOLVING MANAGERS OF A TOP NATIONWIDE FINANCIAL ORGANIZATION
}

\begin{abstract}
This paper presents the main results of a research project that aimed at identifying the main stress factors and diagnosing the occupational stress levels experienced by
\end{abstract}


managers in a large nationwide financial organization working at the organization branch located in the city of Belo Horizonte/MG. The research was conducted under descriptive and explicative research models MTEG (Zille, 2005) and lead to results that pointed out unstable work relations, over dimensioned goals, high levels of worker involvement demanded, work force below actual necessities and poor work inter-relationships as the main stress provokers in managers. Results have shown that 150 out of 168 managers $(89,10 \%)$ were diagnosed as carrying some level of stress, distributed in the following groups: $59(35,21 \%)$ had low to moderated stress levels; $69(40,97 \%)$ had high stress levels and $22(12,92 \%)$ had very high stress levels.

Keywords: Occupational stress. Sources of tension. Managemental function. Financial institutions

\section{REFERÊNCIAS}

AKTOUF, O. Prefácio. In: Gerência em ação: singularidades e dilemas do trabalho gerencial. Rio de Janeiro: FGV, 2005.

ALBRECHT, K. O gerente e o estresse: faça o estresse trabalhar para você. Rio de Janeiro: Zahar, 1990.

ARNOLD, J.; ROBERTSON, I. T.; COOPER, C. L. Work psychology: understanding human behaviour in the workplace. London: Pitman, 1991.

BATEMAN, T. S.; STRASSER, S. A cross-lagged regression test of the relationship between job tension and employee satisfaction. Journal of Applied Psychology, v. 68, p. 439-445, 1983.

CAHILL, P. L.; SCHNALL, P. J. P. The impact of lean production and related new systems of work organization on worker health. Journal of Occupational Health Psychology. v. 4, p. 108-130, 1999.

CARLSON, S. Executive behavior. Appsala Sweden: Textguppen i Uppsala AB, 1951.

CASSIRER, E. Ensaio sobre o homem: introdução a uma filosofia da cultura humana. São Paulo: Martins Fontes, 1994.

CHANLAT, J. F. Mitos e realidade sobre estresse dos gerentes. In: Gerência em ação: singularidades e dilemas do trabalho gerencial. Rio de Janeiro: FGV, 2005. 
COOPER, C. L.; COOPER R. D.; EAKER, L. Living with stress. London: Penguin Books, 1988.

COOPER, R. ASSET. Stress screening questionnaire. London: Robertson Cooper Limited, 2002.

COOPER, C. L. A natureza mutante do trabalho: o novo contrato psicológico e os estressores associados. In: Stress e qualidade de vida no trabalho: perspectivas atuais da saúde ocupacional. São Paulo: Atlas, 2005.

COUTO, H. A. Stress e qualidade de vida dos executivos. Rio de Janeiro: COP, 1987.

. Saúde mental no trabalho: um modelo de abordagem e uma forma de pesquisa nas organizações. Cadernos Ergo - Ergonomia, Saúde e Segurança. Belo Horizonte, n. 3, set., mai. e jun. 2007.

DAVEL, E.; MELO, M. C. O. L. (Orgs.). Gerência em ação: singularidades e dilemas do trabalho gerencial. Rio de Janeiro: FGV, 2005.

FAYOL, H. General and industrial management. London: Pitman, 1949.

FRENCH, W. L. Organization development: theory, pratice, research. Texas: Business Publications, 1983.

FRIEDMAN, M.; ROSENMAN, R. Type A behavior and your heart. New York: Knopf, 1974.

GOLDBERG, P. A saúde dos executivos: como identificar sinais de perigo para a saúde e levar a melhor contra o estresse. Rio de Janeiro: Guanabara, 1986.

KARASEK, R.; TORRES T. Current issues relating to psychosocial job strain and cardiovascular. Journal of Occupational Health Psychology, v. 1, n. 1, p. 9-26, 1996.

KARASEK, R. et al. The job content questionnarie (JCQ): a instrument for internationally comparative assessments of psychosocial job caracteristics. Educational Publishing Fundation. Journal of Occupational Health Psychology, v. 3, n. 4, p. 322-355, 1998. 
KARASEK, R. et al. Psychosocial factories: review of the empirical data among men. Philadelphia: Hanley \& Belfus, Inc. Occupational Medicine, v. 15, n. 1, january-march, 2000.

KATZ, D.; KAHN, R. L. Psicologia social das organizações. São Paulo: Atlas, 1976.

KLIKSBERG, B. A gerência no final do século XX. Revista de Administração Pública, v. 27, n. 2, p. 183-201, abr./jun. 1993.

KOTTER, J. P. The general managers. New York: Amacom, 1982.

LAZARUS, R. S. Personalidade e adaptação. 3. ed. Rio de Janeiro: Zahar, 1974.

LEONTIEV, A. O desenvolvimento do psiquismo. Lisboa: Horizonte Universitário, 1978.

LEMOS, Cristina. Inovação na era do conhecimento. Ciência, Tecnologia e Sociedade, n. 8 , maio/2000.

LEVI, L. Sociedade, Stress e Doença - Investimentos para a saúde e desenvolvimento: causas, mecanismos, conseqüências, prevenção e promoção. III Congresso de Stress da ISMA - BR (International Stress Management Association) e V Fórum Internacional de Qualidade de Vida no Trabalho. Porto Alegre: Anais ... 2003.

. Sociedade, stress e doença-investimentos para a saúde e desenvolvimento: causas, mecanismos, conseqüências, prevenção e promoção. V Congresso de Stress da ISMA - BR (International Stress Management Association) e VII Fórum Internacional de Qualidade de Vida no Trabalho. Porto Alegre: Anais ... 2005.

LHUILHIER, D.; MIGNÈE, C.; RAIX, A. Approches Psychosociales du stress. In: XXI Journées Nationales, Thème 3. Santé Mentale em Milieu de Travail, Rouen, p. 257-261, 1990.

MARQUES, A. L.; MORAES, L. F. R.; PORTES, P. C. P. Qualidade de Vida no Trabalho e Estresse Ocupacional na Polícia Militar de Minas Gerais. Revista de Psicologia Saúde Mental e Segurança Pública. Belo Horizonte, MG, v. 3, p. 53-58, 2003.

MEIRELlES, A. M.; GONÇALVES, C. A. Projetos e relatórios de pesquisa em administração. São Paulo: Atlas, 2004. 
MELO, M. C. O. L.; SPERLING, L. G. Von. Administração pública gerencial: percepção e reação do grupo gerencial intermediário em organizações estatais brasileiras. VII Congreso Internacional del CLAD sobre la Reforma del Estado y de la Administración Pública. Anais... Lisboa: Portugal, 8-11 Oct. 2002.

MINTZBERG, H. The nature of managerial work. New York: Harper \& Row, 1973.

MINTZBERG, H.; LAMPEL, J.; AHLSTRAND, B. Safári de estratégia. Porto Alegre: Bookman, 2000.

MORAES, L. F. R. et al. As dimensões básicas do trabalho, qualidade de vida e stress: uma análise em profissões de impacto na sociedade. In: XIV ENANPAD, SC. Anais..., Belo Horizonte: ANPAD, 1990.

. As dimensões básicas do trabalho, qualidade de vida e stress: uma análise em profissões de impacto na sociedade. Belo Horizonte: CEPEAD/UFMG, 1992 (Relatório de Pesquisa).

Comprometimento organizacional, qualidade de vida e stress no trabalho: uma abordagem de diagnóstico comparativo. Revista Brasileira de Administração Contemporânea, Rio de Janeiro: v. 1, n. 9, p. 170-85, 1995.

MORAES, L. F. R.; MARQUES, A. L.; ZILLE, L. P. Qualidade de vida e estresse organizacional: um estudo comparativo em profissões de risco. Belo Horizonte: CEPEAD/UFMG, 1998 (Relatório de Pesquisa).

Diagnóstico de qualidade de vida e estresse no trabalho da Policia Militar de Minas Gerais. Belo Horizonte: CEPEAD/UFMG, 2000 (Relatório de Pesquisa).

Implicações do treinamento na qualidade de vida e estresse no trabalho (I). Belo Horizonte: CEPEAD/UFMG, 2002 (Relatório de Pesquisa).

Implicações do treinamento na qualidade de vida e estresse no trabalho (II). Belo Horizonte: CEPEAD/UFMG, 2003 (Relatório de Pesquisa).

MOTTA, P. R. Gestão contemporânea: a ciência e a arte de ser dirigente. 2. ed. Rio de Janeiro: Record, 1991. 
NADLER, D. A. et al. Arquitectura organizacional. Rio de Janeiro: Ed. Campus, 1989.

NASCIMENTO, A. B. et al. Os efeitos do estresse sobre o tempo de reação e habilidade de resolução rápida de problemas. In: I Encontro Interno de Psicobiologia, Londrina: Anais..., p. 12-12, 1998.

PERREWÉ, P. L. As conseqüências do humor deprimido no local de trabalho: uma perspectiva teórica. In: Stress e qualidade de vida no trabalho: perspectivas atuais da saúde ocupacional. São Paulo: Atlas, 2005.

QUINLAN, M.; MAYHEW, C.; BOHLE, P. The global expansion of precarious employment, work disorganization, and consequences for occupational health: A review of recent research. International Journal of Health Services, v. 31, p. 335-413, 2001.

RIFKIN, J. O fim dos empregos. São Paulo: Makron Books, 1995.

ROSSI, A. M. Estressores ocupacionais e diferenças de gênero. In: ROSSI, A. M. et al. Stress e qualidade de vida no trabalho: perspectivas atuais da saúde ocupacional. São Paulo: Atlas, 2005.

ROULEAU. L. Gerentes e repertórios de identidade em contexto de reestruturação organizacional. In: DAVEL, E.; MELO, M. C. O. L. (Orgs.). Gerência em ação: singularidades e dilemas do trabalho gerencial. Rio de Janeiro: FGV, 2005.

SAYLES, L. Managerial behavior. New York: McGraw-Hill, 1964.

SAUTER, S. L.; MURPHY, L. R. Abordagens à prevenção do estresse no trabalho dos Estados Unidos. In: ROSSI, A. M. et al. Stress e qualidade de vida no trabalho: perspectivas atuais da saúde ocupacional. São Paulo: Atlas, 2005.

SCHUMPETER, J. The theory of economic development. Cambridge: Harvard University Press, 1938.

SELYE,H. Asyndrome produced by diverse nocuous agents. Nature, v. 138,n. 32, 1936. . The stress of life. McGraw-Hill, 1956. . Stress without distress. Philadelphia: Lippincott, 1974. 
SIMON, H. A. Administrative behavior: a study of decision-making processes. New York: MacMillan, 1947.

SLOAN, A. My years with General Motors. New York: doubleday, 1963.

STEWART, R. Managers and their jobs. London: Pan Piper, 1967.

VERGARA, S. C. Projetos e relatórios de pesquisa em administração. 7. ed. São Paulo: Atlas, 2006.

WEICK, K. E.; QUINN, R. E. Organizational Change and Development. Annual Review of Psychology, n. 50, p. 361-386, 1999.

ZILLE, L. P. Novas perspectivas para a abordagem do estresse ocupacional em gerentes: estudo em organizações brasileiras de setores diversos. 2005. 253f. Tese (Doutorado) - Centro de Pós-Graduação e Pesquisa em Administração, Universidade Federal de Minas Gerais. 